\title{
Successful Reduction of Creatine Kinase and Myoglobin Levels in Severe Rhabdomyolysis Using Extracorporeal Blood Purification (CytoSorb ${ }^{\circledR}$ )
}

\author{
Olcay Dilken Can Ince Ben van der Hoven Sjoerd Thijsse Patricia Ormskerk \\ Hilde R.H. de Geus \\ Department of Intensive Care, Erasmus Medical Centre, University Medical Center, Rotterdam, The Netherlands
}

\section{Keywords}

Microcirculation $\cdot$ Renal failure $\cdot$ Shock $\cdot$ Myoglobin .

CytoSorb

\begin{abstract}
Rhabdomyolysis, if severe, can lead to acute kidney injury (AKI). Myoglobin is an iron and oxygen-binding protein that is freely filtered by the glomerulus. Precipitation of myoglobin in the nephrons' distal parts is responsible for tubular damage with AKI as a consequence. Extracorporeal clearance of myoglobin is conventionally attempted by the use of continuous renal replacement therapy (CRRT) with high cut-off dialysis membranes to limit the extent of the damage. We describe a case of a 56-year-old man with traumatic crush injury and a persistent source of muscle ischaemia unresponsive to high dose CRRT with EMiC-2 filter. Due to therapy failure, he was subsequently treated with the addition of a haemoadsorber $\left(\right.$ CytoSorb $\left.^{\circledR}\right)$ to the circuit. This reduced myoglobin and creatine kinase levels successfully despite ongoing tissue ischaemia. However, CytoSorb ${ }^{\circledR}$ was not enough to maintain microcirculatory perfusion, resulting in the eventual demise of the patient due to severity of the injury. Our report indicates that myoglobin was efficiently removed with CytoSorb ${ }^{\circledR}$ following exchange with the conventional high cut-off filter in continuous venovenous haemodialysis in severe traumatic rhabdomyolysis.

(c) 2020 The Author(s)

Published by S. Karger AG, Basel
\end{abstract}

\section{Introduction}

Rhabdomyolysis is caused by the destruction of striated muscle cells and subsequent release of large quantities of intracellular contents to the circulation, including myoglobin, electrolytes and enzymes [1]. Myoglobin, which is an iron-containing protein weighing $17.8 \mathrm{kDa}$, is the primary nephrotoxic molecule being released in rhabdomyolysis [2]. Renal tubular obstruction, oxidative injury and vasoconstriction of the renal artery are the proposed mechanisms held responsible for the cause of renal injury [2]. Combined with hypovolemia and metabolic acidosis, myoglobinuria may lead to acute kidney injury (AKI) [3]. More than fivefold increased creatine kinase (CK) levels are generally used as a surrogate for diagnosis of rhabdomyolysis [4-6].

Restricting the damage associated with myoglobinuria is fundamental in treatment [4]. Continuous renal replacement therapy (CRRT) with high cut-off protein permeable filter properties is conventionally used to clear myoglobin from the blood [7].

CytoSorb $^{\circledR}$ (Cytosorbents Corporation, Monmouth Junction, NJ, USA) is a haemoadsorption device capable of removing molecules weighing between 10 and $55 \mathrm{kDa}$ including pro-inflammatory cytokines and myoglobin from the blood. It can be used as part of a CRRT circuit $[8,9]$.

Inflammatory mediators such as cytokines underline microcirculatory and parenchymal cell damage. Micro- karger@karger.com www.karger.com/bpu

Karger $\stackrel{\text { ' }}{=}$

BOPEN ACCESS
(C) 2020 The Author(s)

Published by S. Karger AG, Basel

This article is licensed under the Creative Commons AttributionNonCommercial-NoDerivatives 4.0 International License (CC BYNC-ND) (http://www.karger.com/Services/OpenAccessLicense). Usage and distribution for commercial purposes as well as any distribution of modified material requires written permission.
Olcay Dilken

Department of Intensive Care, Erasmus Medical Centre

University Medical Center, Doctor Molewaterplein 40

NL-3015 GD Rotterdam (The Netherlands)

E-Mail olcaydilken@gmail.com 
Fig. 1. Evolution over time of myoglobin level and CK levels during CRRT with EMIC-2 and CRRT with EMIC-2 plus CytoSorb in series. CK, creatine kinase.

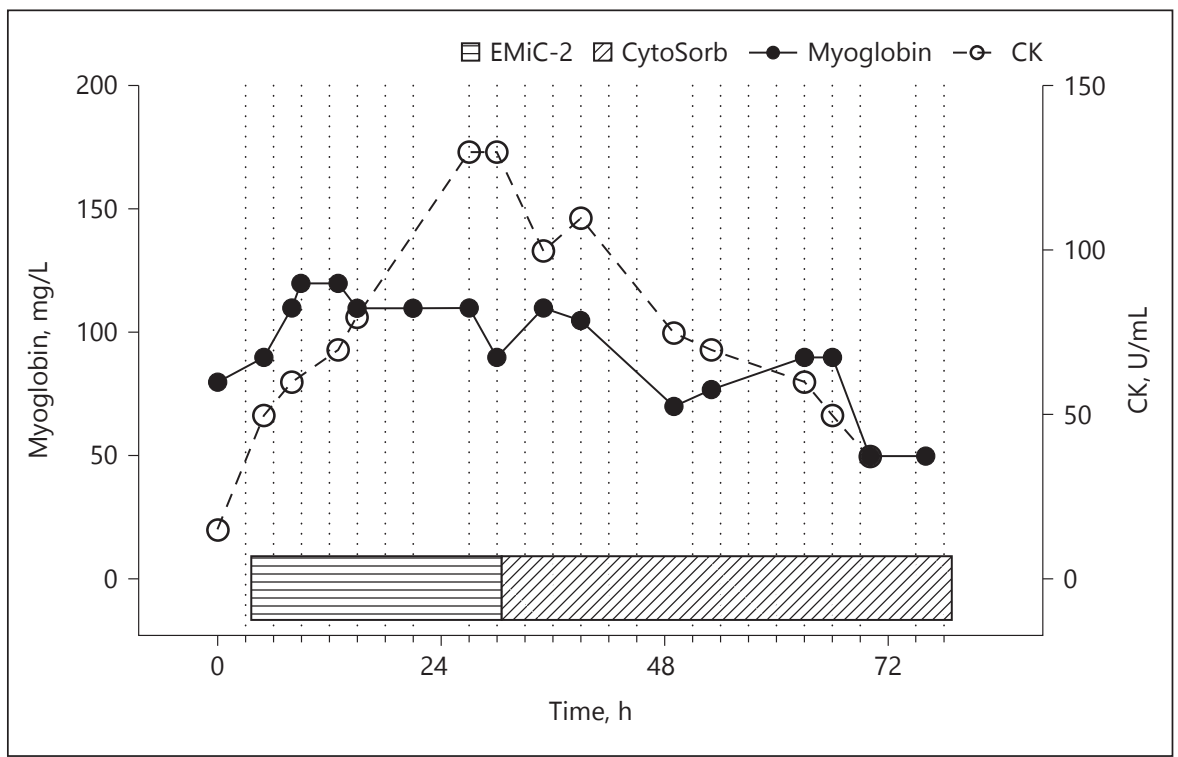

circulatory alterations are associated with organ failure, such as AKI [10]. They can be observed by sublingual microcirculation using handheld vital microscope.

Here we present a case study of fatal rhabdomyolysis first treated with CRRT and high cut-off filter and later, along with a CytoSorb ${ }^{\circledR}$ adsorber for reasons of therapy failure. The effects of the therapies on sublingual microcirculation are monitored by handheld vital microscopy.

\section{Case Report}

This case report describes a 56-year-old male patient, without any previous confirmed medical diagnosis, who suffered severe traumatic rhabdomyolysis of the lower extremities and abdominal wall due to a crush injury.

The patient was awake at the trauma scene. His hypotension and tachycardia were treated with intravenous fluids. Examination in the Emergency Department revealed a hematoma in the pelvic region and ischaemic lower extremities without any arterial pulse signals. Abdominal computed tomography showed a traumatic dissection of the distal aorta and both arteria iliaca, as well as a bilateral transection of the vena femoralis. Also, laboratory diagnostics showed severe rhabdomyolysis, indicated by myoglobin levels of 79,931 $\mu \mathrm{g} / \mathrm{L}$ and CK levels of 15,032 U/L.

The patient was rushed to the Operating Room in an attempt to re-establish arterial supply to the lower extremities. Left arteria femoralis communis and arteria iliaca externa were reconstructed with a synthetic graft. Femoral-femoral crossover construction with a graft from left to right was performed after unsuccessful recanalization of the left iliac artery. Although technically successful, functionality lacked due to persistent ischaemia of $>6 \mathrm{~h}$. Lactate was $6 \mathrm{mmol} / \mathrm{L}$. Bilateral guillotine amputation above the patella was performed.

The patient was postoperatively transferred to the intensive care unit (ICU), and treated with mechanical ventilation and ad- ministration of high-dose noradrenaline ranging between 0.6 and $0.8 \mu \mathrm{g} / \mathrm{kg} / \mathrm{min}$. Broad-spectrum antibiotics were initiated. CRRT with Continuous Veno-Venous Hemo-Dialysis mode was initiated with a high-cut off EMIC-2 dialysis filter (Fresenius Medical Care, Bad Homburg, Germany) to remove excess myoglobin from the bloodstream. The settings were as the following: Blood flow rate: $200 \mathrm{~mL} / \mathrm{min}$, Dialysate flow rate: 4,000 mL/h, Prescribed Renal Dose: $50 \mathrm{~mL} / \mathrm{kg} / \mathrm{h}$ (patient weight: $80 \mathrm{~kg}$ ). No anticoagulation was employed due to severe shock and deranged coagulation parameters (international normalized ratio $>10$ and activated partial thromboplastin time $>180 \mathrm{~s}$ ). Evolution of the kidney functions and myoglobin and CK levels can be seen in Figures 1 and 2 during this phase.

The fluid balance for the first day was $+14,000 \mathrm{~mL}$, and average noradrenaline demand was $1 \mu \mathrm{g} / \mathrm{kg} / \mathrm{min}$. To guide fluid and vasoactive drug therapy, continuous cardiac output monitoring by use of transpulmonary thermodilution $\left(\mathrm{PiCCO}^{\circledR}\right)$ device was applied. Six packs of red blood cells were transfused. Sublingual microcirculation measurement showed a rich and mostly perfused vessel density, which was analyzed by dedicated software [11]: total vessel density (TVD): $22.73 \mathrm{~mm} / \mathrm{mm}^{2}$, percentage of perfused vessels (PPV): 0.93 (online suppl. Video 1; for all online suppl. material, see www.karger.com/doi/10.1159/000505899). As the patients' status did not improve, and neither myoglobin nor potassium levels could not be lowered, a re-exploration surgery was performed, and the vitality of the tissues was assessed. A subsequent laparotomy revealed sigmoid ischaemia, and in response, a proctosigmoidectomy was executed.

Despite the literature $[5,7]$, the EMIC-2 filter alone was not able to prevent progressive myoglobin increase following this procedure. In response, a CytoSorb ${ }^{\circledR}$ adsorber was added to the circuit instead, as shown in [12], on the second day of the ICU stay. Myoglobin levels were lowered significantly from 110,000 to 90,000 $\mu \mathrm{g} / \mathrm{L}$ as well as CK levels from 115,000 to $65,000 \mathrm{U} / \mathrm{L}$ within $4 \mathrm{~h}$ of CytoSorb ${ }^{\circledR}$ treatment. Rapid saturation of the adsorber was noticed necessitating a change of adsorber after $12 \mathrm{~h}$ of initiation. After CytoSorb ${ }^{\circledR}$ replacement, levels again were reduced from 110,000 to 
Fig. 2. Evolution over time of creatinine and urea levels during CRRT with EMIC-2 and CRRT with EMIC-2 plus CytoSorb in series.

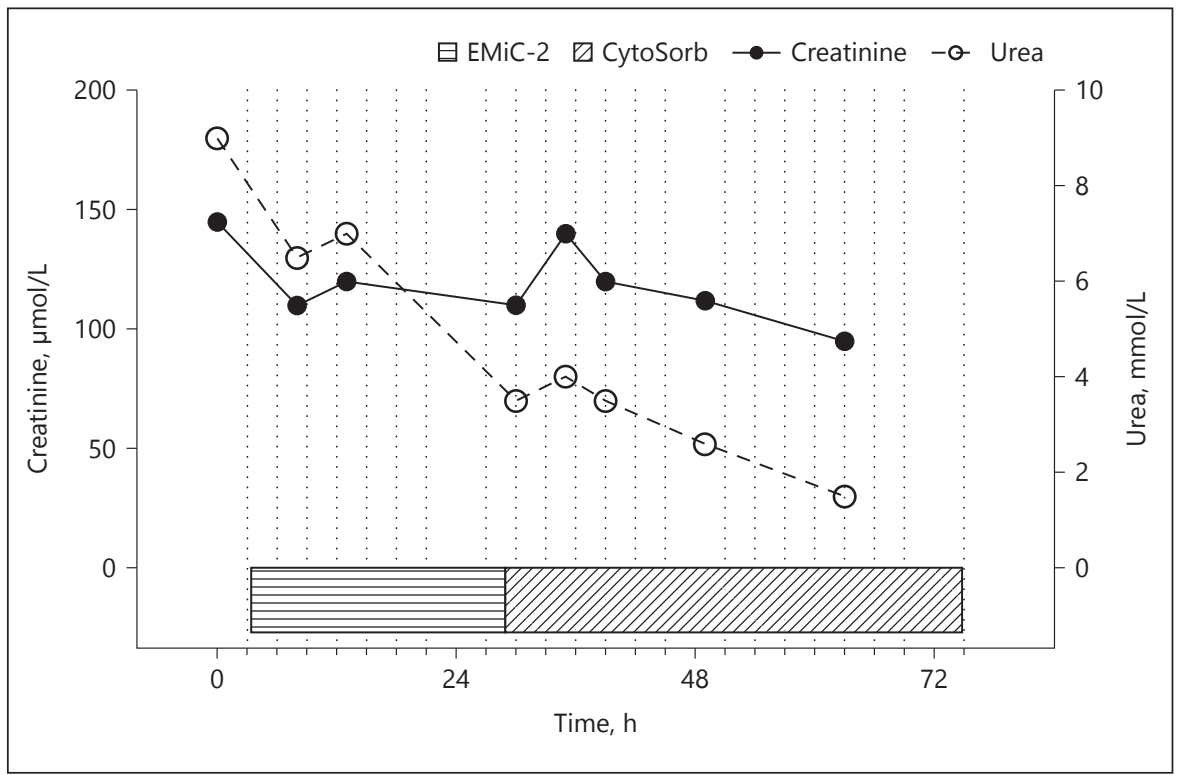

$70,000 \mu \mathrm{g} / \mathrm{L}$ within $12 \mathrm{~h}$. However, noradrenaline consumption could not be lowered, ranging between 1.15 and $1.25 \mu \mathrm{g} / \mathrm{kg} / \mathrm{min}$. The fluid balance was $+9,900 \mathrm{~mL}$. This inquired another re-exploration revealing rectum stump ischaemia. Three packs of red blood cells were transfused. Sublingual microcirculation measurement was similar to day 1 with a TVD of $23.53 \mathrm{~mm} / \mathrm{mm}^{2}$ and PPV of 0.99 .

The patients' condition deteriorated further on day 3 . Noradrenaline consumption hit the highest level of $1.75 \mu \mathrm{g} / \mathrm{kg} / \mathrm{min}$ and could only be lowered to a minimum of $1.15 \mu \mathrm{g} / \mathrm{kg} / \mathrm{min}$ with the help of a renewed CytoSorb ${ }^{\circledR}$ adsorber. Enoximone $1 \mu \mathrm{g} / \mathrm{kg} /$ min and Amiodarone $600 \mathrm{mg}$ over $24 \mathrm{~h}$ were initiated to no avail. Another laparotomy showed total avital rectus abdominis muscles. No further treatment was possible. Despite this unresolved source, myoglobin levels were reduced from 90,000 to 50,000 $\mu \mathrm{g} / \mathrm{L}$ and CK 65,000 to $40,000 \mathrm{U} / \mathrm{L}$. Sublingual microcirculation ceased to flow hours before patients final demise: TVD: $12.46 \mathrm{~mm} / \mathrm{mm}^{2} \mathrm{PPV}$ : 0.06 (online suppl. Video 2). Parallel to this, lactate levels did not normalize. Haemodynamic parameters and blood values associated with the case are shown in Table 1.

\section{Discussion}

Severe rhabdomyolysis often results in myoglobinuria and AKI. High volume CRRT with high cut-off protein filters can be employed to restrict ensuing damage, although this only affects myoglobin levels and not CK. Despite the application of a high cut-off EMiC-2 dialysis filter with a high blood and dialysate rate, myoglobin levels were not reduced significantly, and CK levels increased massively. Blood purification with haemoadsorption has been shown to filter non-specifically pro-inflammatory molecules from the bloodstream. Also, myoglobin has been shown to be filtered in an animal model of smoke and burns injury [13].

Our report shows that the use of CytoSorb ${ }^{\circledR}$ in this severe rhabdomyolysis patient was successful in reducing plasma concentrations of myoglobin and CK despite an unresolved source of bowel ischaemia and unnoticed abdominal wall ischaemia. Furthermore, the CytoSorb $^{\circledR}$ adsorber was shown to be more successful at eliminating myoglobin and $\mathrm{CK}$ than conventional EMiC-2 filter. An adsorber change per $12 \mathrm{~h}$ or even earlier seems plausible in severe cases to ensure continuous mediator reduction.

One could argue that, the demise of the patient could have been the consequence of severe shock which could not be fully resuscitated as indicated by the low cardiac index and high lactate levels. Normalization of the macrohaemodynamic indices was attempted by use of fluids, vasopressors and vasoactive agents in our patient. The high lactate levels despite the resuscitation can be both due to unresolved source and/or flow heterogeneity with oxygen extraction deficit that is seen in patients with septic shock [14]. Although, hyperlactatemia is valuable in the initial phases of shock, haemodynamic coherence rapidly disappears over hours and limits lactate usage in prolonged shock [15]. Additionally, we did not detect any flow heterogeneity in the sublingual microcirculation measurement of the patient in the first 2 days of the ICU stay. It is our interpretation that in this initial phase of systemic haemodynamic compromise, regulatory mechanisms at the regional level were still able to keep the mi- 
Table 1. Hemodynamic and blood values

\begin{tabular}{llcc}
\hline & Day 1 & Day 2 & Day 3 \\
\hline Lactate, mmol/L & 5.1 & 10.1 & 7.8 \\
$\mathrm{ScvO}_{2}, \%$ & 65 & 81 & 69 \\
$\mathrm{Mean}$ arterial pressure, mm Hg & 70 & 70 & 65 \\
Cardiac index, L/min/m & 3.1 & 1.9 & - \\
Heart rate, bpm & 117 & 131 & 100 \\
Hemoglobine, g/dL & 4.6 & 5.5 & 5.2 \\
Fluid balance, mL/day & $+14,000$ & $+9,900$ & $+2,300$ \\
TVD, mm/mm & 22.73 & 23.53 & 6.46 \\
PPV, $\%$ & 93 & 99 & 90,000 \\
Myoglobin*, $\mu \mathrm{g} / \mathrm{L}$ & 79,931 & 110,000 & 65,000 \\
CK*, U/L & 15,032 & 115,000 & 24 \\
Total bilirubine*, $\mu$ mol/L & 6 & 12 & $1,869 / 4,950$ \\
Alanine transaminase*/aspartate transaminase*, U/L & $24 / 30$ & $3,457 / 8,850$ & 18 \\
SOFA score & 16 & 14 & \\
\hline
\end{tabular}

* Peak values are shown.

$\mathrm{ScvO}_{2}$, central venous oxygen saturation; TVD, total vessel density; PPV, percentage of perfused vessels; CK, creatine kinase.

crocirculation perfused. However, following persistent depressed macrocirculation, the microcirculation could no longer be sustained and the alterations we observed set in, followed by the unfortunate death of our patient.

Additionally, our report shows that myoglobin can significantly affect not only the renal perfusion but also systemic tissue perfusion, but the outcomes of this effect may take time to develop. Myoglobin has a considerably lower oxygen half saturation (p50) compared to haemoglobin ( 2.8 vs. $26 \mathrm{~mm} \mathrm{Hg}$ ) and impairs tissue oxygenation by strongly binding to oxygen [16]. Myoglobin also increases vascular resistance, impeding perfusion further [17]. Thus, excess myoglobin can affect 2 determinants of microcirculatory and tissue perfusion, that is, convection and diffusion of oxygen. Persistence in such a condition as in our case, led to the eventual deterioration of the microcirculation too, suggesting that the timing of CytoSorb ${ }^{\circledR}$ application may have been critical and that in such conditions early application of CytoSorb ${ }^{\circledR}$ may be indicated to avoid the progression from normal to abnormal microcirculation.

Lastly, there was a discrepancy in the trends of urea and creatinine levels during CRRT. CRRT was successful in reducing the urea concentration but not the creatinine. Previous studies reported a parallel reduction in both [18-20]. This may have been on account of ongoing muscle destruction.

In summary, this study shows that the haemoadsorbtion with the CytoSorb ${ }^{\circledR}$ adsorber improves both myoglobin and CK clearance compared to the initial high dose
CRRT with EMiC-2 filter. Treatment with CytoSorb ${ }^{\circledR}$ improved the microcirculatory perfusion at day 2 of the ICU stay, despite abnormal macrohaemodynamic parameters showing a loss of haemodynamic coherence. However, injuries were so severe that just the removal of myoglobin and CK did not result in survival at day 3 . This report underscores our opinion the need to install the adsorber in an early phase for removal of inflammatory cytokines and myoglobin.

\section{Statement of Ethics}

Written informed consent to publish the case report was taken from the nearest kin available. The study was conducted according to the principles of the Declaration of Helsinki (version 2013, October; www.wma.net) in accordance with laws and medical research involving humans (WMO) and the requirements of Dutch law regarding human-based research.

\section{Disclosure Statement}

C.I. has received a grant from CytoSorb to commence a randomized controlled trial on the effect of the adsorber on the microcirculation of critically ill patients at the department of Intensive Care of the Erasmus Medical Center Rotterdam. C.I. and his team provide services and training with regard to clinical microcirculation. To this purpose, he runs an internet site called https://www. microcirculationacademy.org. The internet site and its activities are run by a company called Active Medical BV of which he owns 
shares. O.D. received a research grant from the Scientific and Technological Research Council of Turkey (TUBITAK grant no: 1059B191800363). Other authors declare no conflicts of interest.

\section{Funding Sources}

Authors declare no funding source relevant to this case report.

\section{Author Contributions}

H.R.H.G. designed the report concept and acquired the data. O.D., P.O., H.R.H.G., and C.I. analysed and interpret the data. O.D., B.H., and S.T. drafted the manuscript. All authors commented and revised on the manuscript before final agreement.

\section{References}

1 Huerta-Alardín AL, Varon J, Marik PE. Bench-to-bedside review: Rhabdomyolysis an overview for clinicians. Crit Care. 2005 Apr;9(2):158-69.

2 Zimmerman JL, Shen MC. Rhabdomyolysis. Chest. 2013 Sep;144(3):1058-65.

3 Bosch X, Poch E, Grau JM. Rhabdomyolysis and acute kidney injury. N Engl J Med. 2009 Jul;361(1):62-72.

4 Chavez LO, Leon M, Einav S, Varon J. Beyond muscle destruction: a systematic review of rhabdomyolysis for clinical practice. Crit Care. 2016 Jun;20(1):135.

5 Heyne N, Guthoff M, Krieger J, Haap M, Häring HU. High cut-off renal replacement therapy for removal of myoglobin in severe rhabdomyolysis and acute kidney injury: a case series. Nephron Clin Pract. 2012;121(34):c159-64.

6 Petejova N, Martinek A. Acute kidney injury due to rhabdomyolysis and renal replacement therapy: a critical review. Crit Care. 2014 May;18(3):224.

7 Sorrentino SA, Kielstein JT, Lukasz A, Sorrentino JN, Gohrbandt B, Haller H, et al. High permeability dialysis membrane allows effective removal of myoglobin in acute kidney injury resulting from rhabdomyolysis. Crit Care Med. 2011 Jan;39(1): 184-6.
8 Poli EC, Rimmelé T, Schneider AG. Hemoadsorption with CytoSorb ${ }^{\circledR}$. Intensive Care Med. 2019 Feb;45(2):236-9.

9 Rimmelé T, Kellum JA. Clinical review: blood purification for sepsis. Crit Care. 2011;15(1): 205.

10 Ergin B, Kapucu A, Demirci-Tansel C, Ince C. The renal microcirculation in sepsis. Nephrol Dial Transplant. 2015 Feb;30(2):169-77.

11 Hilty MP, Guerci P, Ince Y, Toraman F, Ince C. MicroTools enables automated quantification of capillary density and red blood cell velocity in handheld vital microscopy. Commun Biol. 2019;2(1):2.

12 Wiegele M, Krenn CG. Cytosorb ${ }^{\mathrm{TM}}$ in a patient with Legionella pneumonia-associated rhabdomyolysis: a case report. ASAIO J. 2015 May-Jun;61(3):e14-6.

13 Linden K, Scaravilli V, Kreyer SF, Belenkiy SM, Stewart IJ, Chung KK, et al. Evaluation of the Cytosorb ${ }^{\mathrm{TM}}$ hemoadsorptive column in a pig model of severe smoke and burn injury. Shock. 2015 Nov;44(5):487-95.

14 Ince C, Boerma EC, Cecconi M, De Backer D, Shapiro NI, Duranteau J, et al.; Cardiovascular Dynamics Section of the ESICM. Second consensus on the assessment of sublingual microcirculation in critically ill patients: results from a task force of the European Society of Intensive Care Medi- cine. Intensive Care Med. 2018 Mar;44(3): 281-99.

15 Bakker J. Lactate levels and hemodynamic coherence in acute circulatory failure. Best Pract Res Clin Anaesthesiol. 2016 Dec;30(4):523-30.

16 Gödecke A. Myoglobin: safeguard of myocardial oxygen supply during systolic compression? Cardiovasc Res. 2010 Jul;87(1):4-5.

17 Emig U, Schmidt G, Hellige G, Vetterlein F. Contribution of myoglobin-induced increases in vascular resistance to shock decompensation in experimental Crush-syndrome in anesthetized rats. Shock. 2003 Jan;19(1):79-84.

18 Yasuda H, Uchino S, Uji M, Ohnuma T, Namba Y, Katayama S, et al.; Japanese Society for Physicians and Trainees in Intensive Care Clinical Trial Group. The lower limit of intensity to control uremia during continuous renal replacement therapy. Crit Care. 2014 Oct; 18(5):539.

19 Zhang L, Kang Y, Fu P, Cao Y, Shi Y, Liu F, et al. Myoglobin clearance by continuous venous-venous haemofiltration in rhabdomyolysis with acute kidney injury: a case series. Injury. 2012 May;43(5):619-23.

20 Naka T, Jones D, Baldwin I, Fealy N, Bates S, Goehl H, et al. Myoglobin clearance by super high-flux hemofiltration in a case of severe rhabdomyolysis: a case report. Crit Care. 2005 Apr;9(2):R90-5. 